\title{
Correspondence of the Gardner and van Genuchten/Mualem relative permeability function parameters
}

Teamrat A. Ghezzehei, Timothy J. Kneafsey, and Grace W. Su

Earth Sciences Division, Lawrence Berkeley National Laboratory, Berkeley,

California, USA.

Teamrat A. Ghezzehei, Timothy J. Kneafsey, and Grace W. Su, Earth Sciences Division, Lawrence Berkeley National Laboratory, Berkeley, California, USA (TAGhezzehei@lbl.gov, TJKneafsey@lbl.gov, and GWSu@lbl.gov) 
X - 2 GHEZZEHEI ET AL.: GARDNER AND VAN GENUCHTEN RELATIVE PERMEABILITY FUNCTIONS

1 Abstract. The Gardner and van Genuchten models of relative perme-

2 ability are widely used in analytical and numerical solutions to flow prob-

3 lems. However, the applicability of the Gardner model to real problems is

4 usually limited, because empirical relative permeability data to calibrate the

5 model are not routinely available. In contrast, van Genuchten parameters can

6 be estimated using more routinely available matric potential and saturation

7 data. However, the van Genuchten model is not amenable to analytical so-

s lutions. In this paper, we introduce generalized conversion formulae that rec-

9 oncile these two models. In general, we find that the Gardner parameter $\alpha_{G}$

${ }_{10}$ is related to the van Genuchten parameters $\alpha_{\mathrm{vG}}$ and $n$ by $\alpha_{G} / \alpha_{\mathrm{vG}} \approx 1.3 n$.

${ }_{11}$ This conversion rule will allow direct recasting of Gardner-based analytical

${ }_{12}$ solutions in the van Genuchten parameter space. The validity of the proposed

${ }_{13}$ formulae was tested by comparing the predicted relative permeability of var-

${ }_{14}$ ious porous media with measured values. 


\section{Introduction}

Unsaturated flow in porous media can mathematically be described by Richards' equation

$$
\frac{1}{K_{S}} \frac{\partial \theta}{\partial t}=\nabla \cdot\left[k_{r}(\psi) \nabla \psi\right]+\frac{\partial k_{r}}{\partial z}
$$

where $K_{S}\left[\mathrm{~L} \mathrm{~T}^{-1}\right]$ is saturated hydraulic conductivity, $\psi[\mathrm{L}]$ is matric potential, $\theta\left[\mathrm{L}^{3} / \mathrm{L}^{-3}\right]$ is water content and $k_{r}$ is relative permeability. Analytical solutions to Richards' equation (1), when available, provide powerful insights into the primary features of unsaturated flow problems. Nevertheless, these solutions often come at the cost of extensive simplification of the problem descriptions. Where detailed quantitative analyses are needed, therefore, numerical models are the tools of choice.

One major difference between analytical and numerical approaches is in the descriptions of the constitutive relationship between relative permeability $\left(k_{r}\right)$ and matric potential $(\psi)$. Many analytical solutions depend on a quasilinearization of equation (1) using a simple exponential $k_{r}-\psi$ relationship first introduced by Gardner [1958], whereas numerical solutions typically utilize more flexible relations such as those of Brooks and Corey [1964] and van Genuchten [1980]. Because of these and other differences (e.g., in the definitions of initial and boundary conditions), it is usually difficult to achieve a perfect agreement between analytical solutions and their numerical simulation counterparts.

One approach to reconciling analytical and numerical solutions is to seek correspondence between the parameters of their respective constitutive relations. The objective of this paper is to introduce generalized conversion formulae between the parameters of the 
X - 4 GHEZZEHEI ET AL.: GARDNER AND VAN GENUCHTEN RELATIVE PERMEABILITY FUNCTIONS

35

49

\section{Theoretical Considerations}

Using the Kirchhoff integral transformation

$$
\phi=\int_{-\infty}^{\psi} k_{r} d \psi
$$

the Richards equation (1) can be rewritten as

$$
\frac{1}{K_{S}} \frac{\partial \theta}{\partial t}=\nabla^{2} \phi+\alpha_{*} \frac{\partial \phi}{\partial z}
$$

where $\phi[\mathrm{L}]$ is the Kirchhoff potential and $\alpha_{*}\left[\mathrm{~L}^{-1}\right]=\left(1 / k_{r}\right)\left(d k_{r} / d \psi\right)$ is the sorptive number.

Many analytical and semi-analytical solutions are based on the linearization of the righthand side of equation (3) by assuming that $\alpha_{*}$ is constant [for detailed reviews, see Pullan, 1990; Raats, 2001]. This condition is equivalent to requiring

$$
k_{r} \propto e^{\alpha_{*} \psi}
$$

Gardner [1958] introduced the earliest and most widely used exponential relationship. A modified version of the Gardner model - with finite air-entry pressure - is given by [e.g., Gardner and Mayhugh, 1958]

$$
k_{r}= \begin{cases}1 & \psi \geq \psi_{b} \\ \exp \left[\alpha_{G}\left(\psi-\psi_{b}\right)\right] & \psi<\psi_{b}\end{cases}
$$

where $\alpha_{G}$ is a constant sorptive number (a measure of the pore-size distribution of the medium) and $\psi_{b}$ is air-entry pressure (a function of the largest pore size).

Quasi-linearization of the flow equation (3) has been used to solve numerous multidimensional steady flows, such as surface and subsurface drip sources, flow to sinks, and flow around solid and air-filled obstructions [e.g., Raats, 2001]. However, the application of the 
GHEZZEHEI ET AL.: GARDNER AND VAN GENUCHTEN RELATIVE PERMEABILITY FUNCTIONS $\quad \mathrm{X}-5$

55

quasilinear analyses is often limited to relatively simple geometries and initial/boundary conditions.

Numerical solutions, on the other hand, are not constrained by the need for linearization and often utilize more flexible $\Theta-\psi$ and $k_{r}-\psi$ functions such as the van Genuchten/Mualem model [van Genuchten, 1980; Mualem, 1976]

$$
\begin{gathered}
\Theta=\left[1+\left(\left|\alpha_{\mathrm{vG}} \psi\right|\right)^{n}\right]^{-m} \\
k_{r}=\sqrt{\Theta}\left[1-\left(1-\Theta^{1 / m}\right)^{m}\right]^{2}
\end{gathered}
$$

where $\alpha_{\mathrm{vG}}\left[\mathrm{L}^{-1}\right]$ is a parameter related to the modal pore size, $n$ is a function of the spread of pore-size distribution, and $m=1-1 / n$. The effective saturation $(\Theta)$ is defined as a function of volumetric water content $\theta$, satiated water content $\left(\theta_{s}\right)$, and residual water content $\left(\theta_{r}\right)$ by

67

$$
\Theta=\left(\theta-\theta_{r}\right) /\left(\theta_{s}-\theta_{r}\right)
$$

Typically, van Genuchten parameters are obtained by fitting equation (6) to empirical $\Theta-\psi$ data that are less difficult to measure than $k_{r}-\psi$ data.

Several methods for translating the van Genuchten parameters to Gardner parameters (and vice versa), have been proposed [e.g., Birkholzer et al., 1999; Furman and Warrick, 2005; Morel-Seytoux et al., 1996; Rucker et al., 2005]. Brief summaries of these approaches are given in the next subsection.

\subsection{Previous Approaches}

\subsubsection{Least-Squares Optimization}

The most straightforward approach for estimating the Gardner parameters $\psi_{b}$ and $\alpha_{G}$ using the known van Genuchten $k_{r}-\psi$ function involves minimizing the differences between 
$\mathrm{X}-6$

GHEZZEHEI ET AL.: GARDNER AND VAN GENUCHTEN RELATIVE PERMEABILITY FUNCTIONS

77

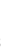

the Gardner and van Genuchten relative permeability curves [e.g., Birkholzer et al., 1999;

Furman and Warrick, 2005]. The number and distribution of matching points for leastsquares fitting can be chosen to provide the best match in the regime of interest. However, the method does not lend itself to derivation of a general correspondence between the Gardner and van Genuchten parameters.

\subsubsection{Capillary-Drive Approach}

In this approach, the Gardner parameters are estimated by matching the effective capillary drive of the Gardner function to that of the van Genuchten function. The effective capillary drive $\left(H_{c}\right)$ is given by [Morel-Seytoux et al., 1996]

$$
H_{c}=\int_{-\infty}^{0} k_{r} d \psi
$$

The $H_{c}$ of the Gardner and van Genuchten functions are obtained by substituting equations (5) and (7) in equation (9), respectively

$$
\begin{gathered}
H_{c(G)}=\psi_{b}+1 / \alpha_{G} \\
H_{c(v G)}=\frac{1}{\alpha_{\mathrm{vG}}} \frac{0.046 m+2.07 m^{2}+19.5 m^{3}}{1+4.7 m+16 m^{2}}
\end{gathered}
$$

The latter is a polynomial fit to numerical evaluation of equation (9) with equation (7) evaluated over a wide range of $m$ values [Morel-Seytoux et al., 1996]. An approximate air-entry pressure $\left(\psi_{b}\right)$ for van Genuchten function was defined by Rucker et al. [2005] as the matric potential that gives some critical relative permeability. For a critical relative permeability of 0.9 , the best-fit polynomial for the van Genuchten $\psi_{b}$ is [Rucker et al., 2005]

$$
\psi_{b}=\frac{1}{\alpha_{\mathrm{vG}}}\left(-2.0692 m^{3}+4.4099 m^{2}-1.5366 m+0.1504\right)^{2}
$$


GHEZZEHEI ET AL.: GARDNER AND VAN GENUCHTEN RELATIVE PERMEABILITY FUNCTIONS $\quad \mathrm{X}-7$

99 
$\mathrm{X}-8$

GHEZZEHEI ET AL.: GARDNER AND VAN GENUCHTEN RELATIVE PERMEABILITY FUNCTIONS

when exploring the implications of Gardner-function based analytical solutions using the equivalent van Genuchten parameters.

\subsection{Proposed Conversion Formulae}

The Gardner [1958] relative permeability function can be uniquely defined using two $\left(\psi, k_{r}\right)$ points. The main task of this paper is to define two characteristic $\psi$ values at which the Gardner [1958] and van Genuchten [1980] should be matched, thereby enabling derivation of algebraic conversion equations.

The Gardner and van Genuchten $k_{r}-\psi$ curves are schematically shown in Figure 1a. On a semi-log chart, the Gardner model is represented by two straight segments intersecting at $\psi=\psi_{b}$ (marked as Point (i) in Figure 1a). On the wet side of the intersection, $k_{r}=1$; whereas on the dry side, $k_{r}$ is on a decreasing straight segment of slope $\alpha_{G}$. In contrast, the van Genuchten model is a smooth and continuous function for all matric potential values.

\subsubsection{First matching point}

We set the air-entry matric potential $\left(\psi=\psi_{b}\right.$ in the Gardner function) to be the first characteristic matching point. The concept of air-entry pressure stems from the observation that, for many porous media, a finite quantity of matric potential $\psi<\psi_{b}$ is needed to create an unsaturated state with relative permeability less than unity. Although the van Genuchten $k_{r}-\psi$ curve does not have such a distinct transition point, careful inspection of typical van Genuchten $\Theta-\psi$ curves reveals that deviation from $\Theta=1$ occurs at matric potential $(\psi)$ values significantly below zero. In Figure 1b, a typical van Genuchten $\Theta-\psi$ curve and its curvature $\left(d^{2} \Theta / d \psi^{2}\right)$ are plotted. Negative curvature denotes downward concavity. Figure 1b shows that the curvature has two local extreme values. At the point 
of maximum downward concavity of the $\Theta-\psi$ curve (denoted by a circular symbol in Figure 1b), the effective saturation $\Theta$ begins to rapidly drop below unity. For the purpose of matching with the Gardner $k_{r}-\psi$ function, we define this point as the air-entry matric potential of the van Genuchten $k_{r}-\psi$ function. Accordingly, the point of maximum curvature should satisfy

$$
d^{3} \Theta / d \psi^{3}=0 \text { and } d^{2} \Theta / d \psi^{2}<0
$$

After substituting equation (6) in equation (15) and performing elementary algebraic manipulations, we arrive at

$$
\psi_{b}=\frac{1}{\alpha_{\mathrm{vG}}} \cdot\left\{\frac{5 m-m^{2}+\sqrt{8 m+5 m^{2}-2 m^{3}+m^{4}}}{4 m^{2}-2 m}\right\}^{m-1}
$$

Note that the denominator of equation (15) has real values only for $m>0.5(n>2)$; hence, the air-entry pressure of van Genuchten $k_{r}-\psi$ function exists only within this range. The implications of this limit will be further examined at the end of this section.

\subsubsection{Second matching point}

The second point needed to uniquely define the Gardner $k_{r}-\psi$ function can be placed anywhere along the sloping segment. In the following, we seek a $\psi$ value in the van Genuchten $k_{r}-\psi$ function that represents the most nonlinear regime to be the second matching point. Note that the right-hand side of Richards equation (3) becomes nonlinear when the sorptive number $\alpha_{*}$ varies with $\psi$ (i.e., $\left.\alpha_{*}(\psi)=d \ln [K(\psi)] / d \psi\right)$ and the strongest nonlinearity should occur in the regimes that result in the largest $\left|d \alpha_{*}(\psi) / d \psi\right|$. Thus, the special value of matric potential $\psi=\psi_{*}$ representing the maximum nonlinearity satisfies

$$
\frac{d^{2} \alpha_{*}(\psi)}{d \psi^{2}}=0
$$


X - 10 GHEZZEHEI ET AL.: GARDNER AND VAN GENUCHTEN RELATIVE PERMEABILITY FUNCTIONS

For the van Genuchten relative permeability function (6), the values of $\psi_{*}$ can be obtained by numerically evaluating (17) using equations (7) and (6). The values of $\psi_{*} \cdot \alpha_{\mathrm{vG}}$ in the range $0.5<m<1$ (plotted in Figure 2) indicate that the neighborhood of $\psi=1 / \alpha_{\mathrm{vG}}$ represents the highest nonlinearity. Therefore, we set $\psi=1 / \alpha_{\mathrm{vG}}$, marked as point (ii) in Figure 1a, as the second characteristic matching point, so that both the van Genuchten and Gardner functions comparably describe this highly nonlinear portion of the $k_{r}-\psi$ relationship.

\subsubsection{Approximation of sorptive number}

In the preceding subsections, we defined two characteristic matric potential values in the van Genuchten relative permeability function (7) that represent the onset of unsaturated conditions and the maximum nonlinearity. Using these characteristic points, the slope of the Gardner $k_{r}-\psi$ function on a semi-log chart is expressed by

$$
\alpha_{G}=-\frac{\ln (1)-\ln \left[k_{r}\left(1 / \alpha_{\mathrm{vG}}\right)\right]}{\psi_{b}-1 / \alpha_{\mathrm{vG}}}
$$

Substituting equation (7) in equation (18) and carrying out algebraic manipulation gives

$$
\alpha_{G}=-\frac{\ln \left[\left(2^{-5 m / 4}\left(1-2^{m}\right)\right)^{2}\right]}{\psi_{b}-1 / \alpha_{\mathrm{vG}}}
$$

where $\psi_{b}$ is as given by equation (16). The equivalence of the Gardner and van Genuchten parameters is visualized best when plotted in dimensionless form. Notice that the parameters $\alpha_{G}, \psi_{b}$, and $\alpha_{\mathrm{vG}}$ have the same unit as the matric potential $\psi$, whereas $n$ and $m$ are dimensionless. In Figure 3, the ratios $\alpha_{G} / \alpha_{\mathrm{vG}}$ and $\psi_{b} / \alpha_{\mathrm{vG}}^{-1}$ are plotted against the van Genuchten parameter $n$. From Figure 3, it is evident that $\alpha_{G} / \alpha_{\mathrm{vG}}$ can be linearly related to $n$ by the following fitting curve (with $r^{2}=0.99$ )

$$
\frac{\alpha_{G}}{\alpha_{\mathrm{vG}}} \approx 1.3 n
$$


GHEZZEHEI ET AL.: GARDNER AND VAN GENUCHTEN RELATIVE PERMEABILITY FUNCTIONS X - 11

Equation (20) provides a concise conversion formula that can also be extrapolated to $n<2$ as shown in Figure 3. Similarly, a concise conversion rule for the air-entry pressure is given by the following power-law fit (with $r^{2}=0.99$ )

$$
\psi_{b} \cdot \alpha_{\mathrm{vG}} \approx 1-(n / 2)^{-1.163} \text { for } n>2
$$

However, equation (21) cannot be extrapolated to $n \leq 2$ because it results in unphysical positive air-entry pressure. Thus, we restrict the air-entry pressure of the van Genuchten function in the $n \leq 2$ range to $\psi_{b}=0$.

\section{Illustrative Examples}

In this section, we test the validity of the concise conversion equations (20) and (21). Recall that the van Genuchten and Gardner $k_{r}-\psi$ functions (as used in this paper) are predictive models. Therefore, the ultimate test of their validity is achieved by comparing them with measured $k_{r}-\psi$ values. We selected $12 \Theta-\psi$ and $k_{r}-\psi$ data sets that were used by Brooks and Corey [1964], van Genuchten [1980] and Tuller and Or [2001]. These data sets cover a broad range of porous media, ranging from loose, fragmented mixture to clay soil. The van Genuchten parameters of these media were obtained by fitting equation (6) to the measured $\Theta-\psi$ data. Corresponding Gardner parameters were calculated using three different approaches. The first approach is direct fitting of equation (5) to the $k_{r}-\psi$ data sets. Best-fit Gardner parameters were obtained by minimizing the residuals $(r)$ between the measured and predicted log-transformed relative permeabilities:

$$
r=\exp \left[\frac{1}{N} \sum\left|\log \left(k_{r}^{P}\right)-\log \left(k_{r}^{M}\right)\right|\right]
$$

where $k_{r}^{P}$ and $k_{r}^{M}$ are predicted and measured relative permeabilities, respectively, and $N$ is the number of data points. In addition, Gardner parameters were estimated based on the 
X - 12 GHEZZEHEI ET AL.: GARDNER AND VAN GENUCHTEN RELATIVE PERMEABILITY FUNCTIONS

corresponding van Genuchten parameters, using the capillary-drive approach (equations

12 and 13) and the conversion formulae introduced in this paper (equations 20 and 21). The predicted van Genuchten and Gardner $k_{r}-\psi$ curves, along with the measured data, of all the example porous media are shown in Figure 4, and a summary of the van Genuchten and Gardner parameters is given in Table 1. From Figure 4, it is apparent that the predicted Gardner curves based on the formulae introduced in this paper are, in most cases, comparable to or better than the van Genuchten curves. In contrast, the Gardner curves that are based on the effective-capillary drive approach poorly match the measured values, with the exception of Silt Loam GE\#3 $(m \approx 0.5)$.

For the porous media with $n<2$, both the van Genuchten and Gardner models fail to capture the pattern of the measured $k_{r}-\psi$ data. The major deviation of the van Genuchten prediction from the measured values occurs at a relative permeability of about $10^{-5}$, which could be attributed to significantly different modes of flow at moderate to high saturations versus very low saturations. Tuller and Or [2001] argue that at very low saturations, the predominant flow mechanism is not through capillary pools (the underlying assumption behind the van Genuchten model) but that of adsorbed films. For this reason, the data points that are believed to be inconsistent with the bundle of capillaries concept (open circles in Figure 4) were not used in fitting the Gardner equation to the measured data.

As an objective measure of the goodness of fit, the Gardner parameters calculated using the formulae proposed herein and the effective capillary drive approach were compared with the fitted parameters. In Figure $5, \alpha_{G} / \alpha_{\mathrm{vG}}$ is plotted against the van Genuchten parameter $m$. The curves in Figure 5 are the results of the predictive models and the symbols are the direct fits. It is apparent that the match between the fitted values and the 
GHEZZEHEI ET AL: GARDNER AND VAN GENUCHTEN RELATIVE PERMEABILITY FUNCTIONS X - 13

formulae introduced herein is good. Note that the misfit between the predicted and fitted parameter results partly from the weakness of the van Genuchten model in predicting the measured $k_{r}-\psi$ data. The porous media with the highest deviations between the predicted parameters (using the formulae introduced in this paper) and the fitted values are those for which the van Genuchten $k_{r}-\psi$ curves did not result in good agreement with the measured data. In contrast, the capillary-drive approach matches the fitted parameters only in the neighborhood of $n=2(m=0.5)$, such as the Silt Loam GE \#3 (see Figure 4c).

\section{Applications}

The most useful application of the Gardner $k_{r}-\psi$ function has been developing analytical and semi-analytical solutions to flow and transport problems. In such quasilinear analyses, the characteristic quantity $\alpha_{G} / 2$ is a useful measure of macroscopic capillary length [Pullan, 1990] that enters the dimensionless quantity $s$ (sorptive length), a measure of the relative importance of gravity and capillarity in determining flow,

$$
s=\frac{1}{2} \alpha_{G} l
$$

where $l$ is a problem-specific characteristic physical length. This quantity appears in many analytical solutions [e.g., Philip et al., 1989] and semi-analytical solutions. The proposed conversion equation (20) allows direct recasting of $s$ in terms of van Genuchten parameters

$$
s \approx \frac{1.3}{2} n \alpha_{\mathrm{vG}} l
$$

Equation (24) combines the effects of the major hydrologic properties $\left(\alpha_{\mathrm{vG}}\right.$ and $\left.n\right)$ with the physical characteristic length $l$ in a single parameter. In a subsequent communication (Ghezzehei et al., Nature of the dry shadow below cavities in unsaturated media, 
X - 14 GHEZZEHEI ET AL.: GARDNER AND VAN GENUCHTEN RELATIVE PERMEABILITY FUNCTIONS

manuscript in preparation) we show that this rather compact representation of multiple variables allows generalization of van Genuchten-based numerical solutions in dimensionless form. Moreover, equations (20) and (21) can be used to present results of analytical and semi-analytical solutions in terms of saturation.

\section{Summary and Conclusions}

The exponential relationship between relative permeability and matric potential introduced by Gardner [1958] is routinely used in derivation of analytical and semi-analytical solutions to flow problems in porous media. However, the practical application of these solutions is limited by the scarcity of empirical relative permeability data needed to calibrate the Gardner model. As an alternative, models that predict relative permeability based on matric potential versus saturation relations are used - one such widely used model is that of van Genuchten [1980]. However, van Genuchten's model is not suitable for derivation of analytical solutions. In this paper, we introduced algebraic formulae for converting the van Genuchten parameters to Gardner parameters (or vice versa). In particular, we showed that the ratio of the Gardner parameter $\alpha_{G}$ to the van Genuchten parameter $\alpha_{\mathrm{vG}}$ is related to the van Genuchten parameter $n$ by $\alpha_{G} / \alpha_{\mathrm{vG}}=1.3 n$. This simple relation enables the recasting of analytical solutions derived using the Gardner model in terms of the equivalent van Genuchten parameters. Comparingrelative permeabilities predicted using the Gardner model with measured values showed that the proposed formulae perform as well as the van Genuchten equation for $n$ parameter values greater than two. For small $n$ values, the performance of both the van Genuchten and Gardner models is less satisfactory. 
GHEZZEHEI ET AL: GARDNER AND VAN GENUCHTEN RELATIVE PERMEABILITY FUNCTIONS X - 15

Acknowledgments. This work is supported by Office of Science and Technology and International, Office of Civilian Radioactive Waste Management. Careful reviews and suggestions for improvement by Hui-Hai Liu and Stefan Finsterle are gratefully acknowledged.

\section{References}

Birkholzer, J., G. M. Li, C. F. Tsang, and Y. Tsang, Modeling studies and analysis of seepage into drifts at yucca mountain, J. Contam. Hydrol., 38, 349-384, 1999.

Brooks, R. H., and A. T. Corey, Hydraulic properties of porous media, hydrology paper no. 3, Tech. rep., Civil Engineering Dept, University of Colorado, 1964.

Furman, A., and A. W. Warrick, Unsaturated flow through spherical inclusions with contrasting sorptive numbers, Vadose Zone Journal, 4, 255-263, 2005.

Gardner, W., Some steady-state solutions of the unsaturated moisture flow equation with application to evaporation from a water table, Soil Sci., 85, 228232, 1958.

Gardner, W. R., and M. S. Mayhugh, Solutions and tests of the diffusion equation for the movement of water in soil, Soil Sci. Soc. Am. P., 22, 197-201, 1958.

Morel-Seytoux, H. J., P. D. Meyer, M. Nachabe, J. Touma, M. T. vanGenuchten, and R. J. Lenhard, Parameter equivalence for the brooks-corey and vangenuchten soil characteristics: Preserving the effective capillary drive, Water Resour. Res., 32, 1251-1258, 1996.

Mualem, Y., New model for predicting hydraulic conductivity of unsaturated porousmedia, Water Resour. Res., 12, 513-522, 1976.

Philip, J. R., Comments on steady infiltration from spherical cavities - reply, Soil Science Society of America Journal, 49, 788-789, 1985. 
Philip, J. R., J. H. Knight, and R. T. Waechter, Unsaturated seepage and subterranean holes - conspectus, and exclusion problem for circular cylindrical cavities, Water Resour. Res., 25, 16-28, 1989.

Pullan, A. J., The quasi-linear approximation for unsaturated porous-media flow, Water Resour. Res., 26, 1219-1234, 1990.

Raats, P. A. C., Developments in soil-water physics since the mid 1960s, Geoderma, 100, 355-387, 2001, sp. Iss. SI.

Rucker, D. F., A. W. Warrick, and T. P. A. Ferre, Parameter equivalence for the gardner and van genuchten soil hydraulic conductivity functions for steady vertical flow with inclusions, Adv. Water Resour., 28, 689-699, 2005.

Tuller, M., and D. Or, Hydraulic conductivity of variably saturated porous media: Film and corner flow in angular pore space, Water Resour. Res., 37, 1257-1276, 2001.

van Genuchten, M. T., A closed-form equation for predicting the hydraulic conductivity of unsaturated soils, Soil Sci. Soc. Am. J., 44, 892-898, 1980, soil Sci. Soc. Amer. J.

Warrick, A. W., Correspondence of hydraulic functions for unsaturated soils, Soil Sci. Soc. Amer. J., 59, 292-299, 1995. 


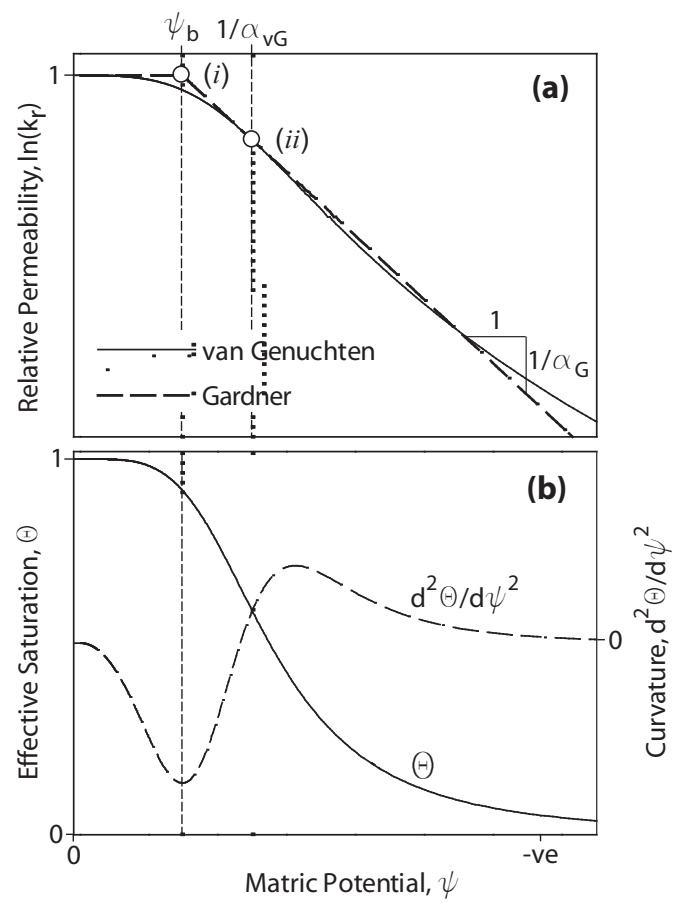

Figure 1. Schematic diagrams showing (a) Gardner and van Genuchten relative permeability curves and (b) a van Genuchten retention curve along with its curvature. 


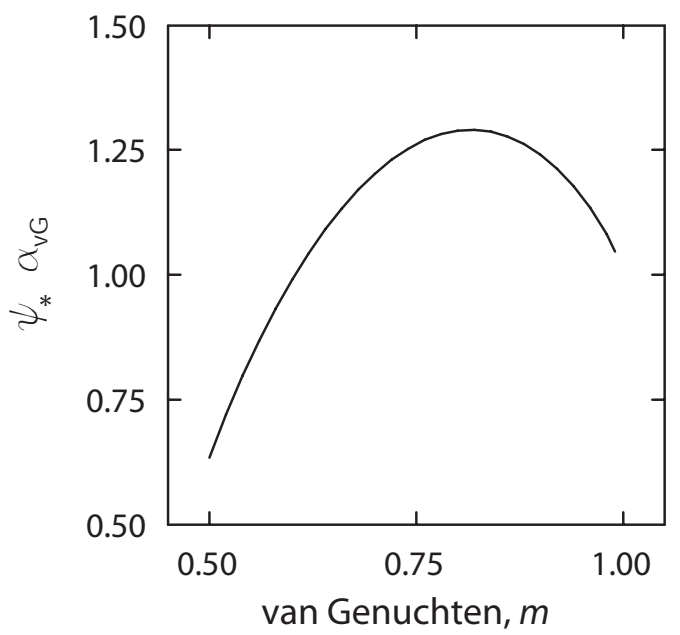

Figure 2. Values of $\psi$ that give the highest $\left|d \alpha_{*}(\psi) / d \psi\right|$ for the van Genuchten relative permeability function.

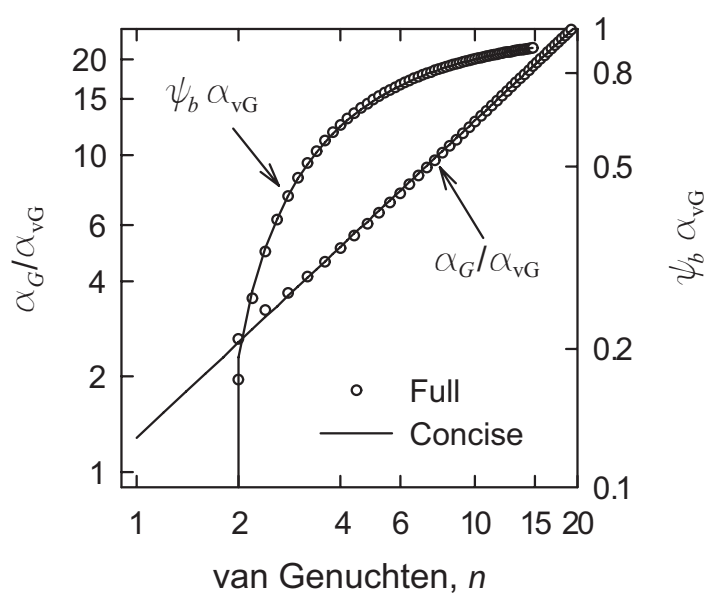

Figure 3. Correspondence of Gardner and van Genuchten parameters. 
Table 1. Fitted van Genuchten parameters $(v G)$ and Gardner parameters calculated by direct fitting $\left(G_{F i t}\right)$, capillary-drive method $\left(G_{C D}\right)$, and formulae introduced in this paper $\left(G_{N e w}\right)$ for example porous media

\begin{tabular}{|c|c|c|c|c|c|c|c|c|}
\hline \multirow[b]{2}{*}{ Material Name } & \multicolumn{2}{|c|}{$v G$} & \multicolumn{2}{|c|}{$G_{F i t}$} & \multicolumn{2}{|c|}{$G_{C D}$} & \multicolumn{2}{|c|}{$G_{N e w}$} \\
\hline & $\alpha_{\mathrm{vG}}$ & $n$ & $\alpha_{G}$ & $\psi_{b}$ & $\alpha_{G}$ & $\psi_{b}$ & $\alpha_{G}$ & $\psi_{b}$ \\
\hline Hygiene Sandstone $^{\mathrm{a}}$ & 0.79 & 10.40 & 10.39 & 1.11 & 4.36 & 0.89 & 10.45 & 1.09 \\
\hline Touchet Silt Loamª & 0.50 & 1.09 & 3.33 & 1.30 & 2.18 & 1.19 & 4.48 & 1.58 \\
\hline Silt Loam GE\# $3^{\text {a }}$ & 0.42 & 2.06 & 1.24 & 0.11 & 1.17 & 0.14 & 1.20 & 0.21 \\
\hline Volcanic Sand ${ }^{\mathrm{b}}$ & 4.57 & 7.44 & 39.34 & 0.16 & 20.51 & 0.13 & 42.91 & 0.17 \\
\hline Glass Beads $^{\mathrm{b}}$ & 3.15 & 20.52 & 54.86 & 0.28 & 24.07 & 0.26 & 83.45 & 0.30 \\
\hline Fine Sand GE\#13 & 2.09 & 7.09 & 27.42 & 0.40 & 9.10 & 0.29 & 18.71 & 0.38 \\
\hline Fragmented Mix ${ }^{\mathrm{b}}$ & 4.56 & 7.92 & 35.55 & 0.16 & 21.33 & 0.14 & 45.69 & 0.18 \\
\hline Berea Sandstone ${ }^{\mathrm{b}}$ & 1.94 & 9.06 & 19.44 & 0.38 & 9.89 & 0.34 & 22.35 & 0.43 \\
\hline Beit Netofa Clay ${ }^{c}$ & 0.15 & 1.17 & 0.82 & 0.00 & 2.71 & 0.001 & 0.22 & 0.0 \\
\hline Gilat Loamc & 2.29 & 1.67 & 6.08 & 0.22 & 8.08 & 0.005 & 4.88 & 0.0 \\
\hline Sandy Loam ${ }^{\mathrm{c}}$ & 1.42 & 1.47 & 1.02 & 0.00 & 6.87 & 0.001 & 2.67 & 0.0 \\
\hline Clay Loam ${ }^{c}$ & 0.54 & 1.24 & 0.19 & 0.00 & 5.94 & 0.0 & 0.86 & 0.0 \\
\hline
\end{tabular}

\footnotetext{
a van Genuchten [1980]

b Brooks and Corey [1964]

c Tuller and Or [2001]
} 

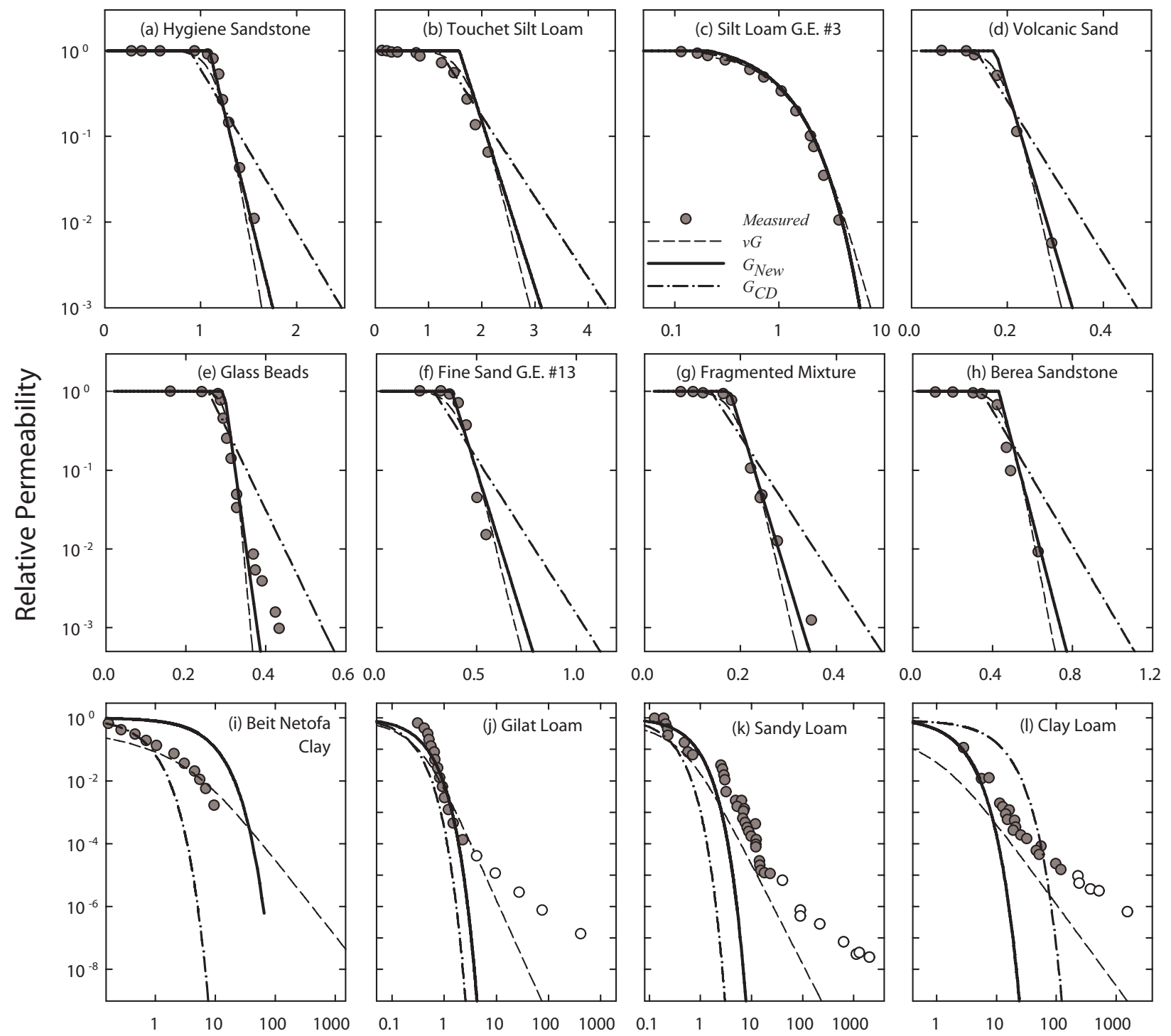

Capillary Pressure (m)

Figure 4. Illustrative examples comparing relative permeability functions predicted using van Genuchten $(v G)$ and Gardner equations with measured data. Notation: $v G$ $=$ van Genuchten curve, $G_{N e w}=$ Gardner curve using conversion formulae introduced in this paper, and $G_{C D}=$ Gardner curve using capillary drive method. 


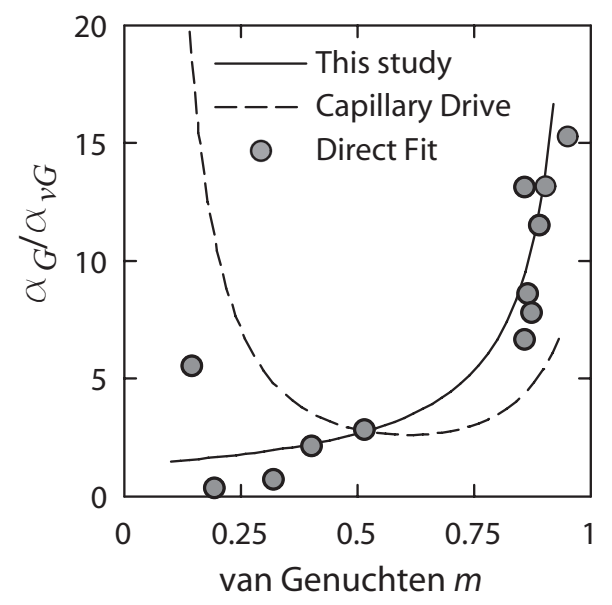

Figure 5. Comparison of Gardner parameters predicted using conversion formulae introduced in this paper (equations 20 and 21) and the capillary-drive approach (equations 12 and 13) with parameters obtained by direct fitting of the Gardner model (5) to measured $k_{r}-\psi$ data sets. 